\title{
Inflammatio us a procoagulant state for appearing thrombus in patient with secondary dilated cardiomyopathy
}

\section{Introduction}

Inflammatio is the dinamic prosess of defence made of cronological changes which are repercussions of the body on injury or infection, It is made of complex biological and biochemical reactions which includes crucial cells of the immune system and many lots of biological mediators stimulated with mechanical injuries, toxins, infections and reaction hypersensitivity. ${ }^{1,2}$ Because of the disorders of the homeostatic system it is biger probability of appearing thromboembolic incidence especially in patients with some disorders. Dilated cardiomyopathy is disease with structural and functional changes of heart muscle. In the following case report the 43-year-old male with earlier known secondary dilated cardiomyopathy who presented with a pneumonia and thrombus in left and right heart ventricul..$^{3-5}$

\section{Case report}

A 44-year-old male patient with with earlier known secondary dilated cardiomyopathy (from 2014. post myocardial) ${ }^{6}$ was hospitalizated because of right pneumonia and cardial decompensation (he was presentened with dyspnea and chest pain and with eleveted inflamatio markers and D-dimer nad NT PRO BNP). Because of chest pein we did the CT pulmonary angiography and we seclude pulmonic embolismus. ${ }^{7}$ Echocardiography exam show us the dilatated left ventricul (EDD $75 \mathrm{~mm}$ ) thinned wall in basal and medium parts of posterior and inferior wall and left wall were poorly movable with akinetic apical part with formatio $(7 \mathrm{x} 6 \mathrm{~mm})$ with EF LV by Simpson Biplane $25-28 \%$. Dilatated DA $(18 \mathrm{~cm} 2)$ and DV $(40 \mathrm{~mm})$ reduced contractility TAPSE $13 \mathrm{~mm}$ TDI s' $8 \mathrm{~cm} / \mathrm{s}$. FAC $=20.4 \%$ ( EFDV around $30 \%$ ). In the DV formatio (32x22mm) ${ }^{8-10}$ PR $111 \mathrm{~ms}$ RVSP 23 $\mathrm{mmHg}$ with MR middle grade to sever. With the TEE we confirm the formation $(20 \times 30 \mathrm{~mm})$ and the fondatio wih is a thrombus in the apical part of the left ventricul. With the antibiotic therapy (piperaciklin with tazobactam and then with azitromicin and tetraciklin and with the other conservatory therapy) we achieve regression of pneumonia and cardiac recompensatio. In the further processing (in the tertial institution)with the MR we prove that the formation in the left and the right heart was thrombus. The patient was preparated for the transplantation of the heart.

\section{Conclusion}

Every additional disease can complicated the earlier known heart disease especially with inflammation which has the procoagulant activity that encourages appearing thrombus. We must be more careful in the patient with some of the heart disease so that we dont predict it. Keywords: dilated cardiomyopathy, pneumonia, thrombus, echocardiography (tranthoracal and transesophageal).
Volume 12 Issue 4 - 2019

\author{
Andreja Čleković Kovačić \\ Department of Internal medicine, General Hospital Bjelovar, \\ Croatia
}

Correspondence: Andreja Čleković Kovačić, Department of Internal medicine, General Hospital Bjelovar,A. Mihanovića 8, 43 000 Bjelovar, Croatia, Tel +385 4327918I,

Email kovacicandrejal@gmail.com

Received: May 19, 2019 | Published: July II, 2019

\section{Conflicts of interest}

Authors declare that there are no conflicts of interest.

\section{References}

1. Schmid Schönbein GW. Analysis of inflammation. Annu Rev Biomed Eng. 2006;8:93-131.

2. Schmid Schönbein GW, Hugli TE. A new hypothesis for microvascular inflammation in shock and multiorgan failure: self-digestion by pancreatic enzymes. Microcirculation. 2005;12(1):71-82.

3. Claudiu T Supuran. Antiinflamm Antiallergy Agents Med Chem. Bentham Sceince. 2019;18(1):71-79.

4. Bendtzen K Ugeskr Laeger. The immune system and inflammatory diseases. Review. 2008;170(24):2110-2115.

5. Herrington C, Hall PA. Molecular and cellular themes in inflammation and immunology. J Pathol. 2008;214(2):123-125.

6. Mescher AL, Neff AW. Regenerative capacity and the developing immune system. Adv Biochem Eng Biotechnol. 2005;93:39-66.

7. Parker $A B$, Yusuf $S$, Naylor $C D$. The relevance of subgroup-specific treatment effects: the Studies Of left ventricular Dysfunction (SOLVD) revised. Am Heart J. 2002;144(6):279-283.

8. Poole-Wilson PA, Uresky BF, Thygesen K, et al. Mode of death in heart failure: findings from the ATLAS trial. Heart. 2003;89(1):42-48.

9. Ronco C, Cicoira M, Mc Cullough PA. Pathophysiological Crosstalk Leading to Combined Heart and Kidney Dysfunction in the Setting of Acutely Decompensated Heart Failure. $J$ Am Coll Cardiol. 2012;60(12):1031-1042.

10. De Boer RA, Voors AA, Mutendam P, et al. Galectin-3: a novel mediator of heart failure development and progressio. Eur J Heart Fail. 2009;11(9):811-817.

\section{Acknowledgments}

None. 